\title{
Challenges and strategies for cohort retention and data collection in an indigenous population: Australian Aboriginal Birth Cohort
}

\author{
Megan Lawrance ${ }^{1}$, Susan M Sayers ${ }^{1 *}$ and Gurmeet R Singh ${ }^{1,2}$
}

\begin{abstract}
Background: Longitudinal prospective birth cohort studies are pivotal to identifying fundamental causes and determinants of disease and health over the life course. There is limited information about the challenges, retention, and collection strategies in the study of Indigenous populations. The aim is to describe the follow-up rates of an Australian Aboriginal Birth Cohort study and how they were achieved.

Methods: Participants were 686 babies enrolled between January 1987 and March 1990, born to a mother recorded in the Delivery Suite Register of the Royal Darwin Hospital (RDH) as a self-identified Aboriginal. The majority of the participants (70\%) resided in Northern Territory within rural, remote and very remote Aboriginal communities that maintain traditional connections to their land and culture. The Aboriginal communities are within a sparsely populated (0.2 people/ km2) area of approximately 900,000 km2 (347sq miles), with poor communication and transport infrastructures. Follow-ups collecting biomedical and lifestyle data directly from participants in over 40 locations were conducted at 11.4 years (Wave-2) and 18.2 years (Wave-3), with Wave-4 follow-up currently underway.

Results: Follow-ups at 11 and 18 years of age successfully examined $86 \%$ and $72 \%$ of living participants respectively. Strategies addressing logistic, cultural and ethical challenges are documented.

Conclusions: Satisfactory follow-up rates of a prospective longitudinal Indigenous birth cohort with traditional characteristics are possible while maintaining scientific rigor in a challenging setting. Approaches included flexibility, respect, and transparent communication along with the adoption of culturally sensitive behaviours. This work should inform and assist researchers undertaking or planning similar studies in Indigenous and developing populations.
\end{abstract}

Keywords: Epidemiological method, Prospective longitudinal cohort, Ethnic minority, Health determinants, Australian, Aboriginal

\section{Background}

A prospective longitudinal study of a birth cohort is a well recognized way of identifying the temporal causes and determinants of disease and health over the life course. As a result, birth cohort studies are being maintained for many years, including some that are now in their seventh decade $[1,2]$, and new birth cohorts are being established [3-6]. International collaborations of cohort studies are also being encouraged, particularly in societies undergoing

\footnotetext{
* Correspondence: sue.sayers@menzies.edu.au

${ }^{1}$ C/-Menzies School of Health Research, Institute of Advanced Studies, Charles Darwin University, PO Box 41096, Casuarina, NT 0810, Australia Full list of author information is available at the end of the article
}

economic and demographic transitions [7]. Despite these initiatives, there is limited information about the life course of disease in Indigenous and developing populations, even though these populations contribute disproportionably to the burden of non-communicable disease world-wide, namely high rates of diabetes and cardiovascular heart disease [8].

In the Northern Territory (NT) of Australia, the Aboriginal population has concurrently high rates of low birth weight, infant under-nutrition and infection, as well as adult diabetes, renal disease and cardiovascular disease, all contributing to a disproportionately high rate of premature adult death. 
In 1987 a prospective longitudinal study of an Australian Aboriginal Birth Cohort $(\mathrm{ABC})$ was established with a focus on the development of chronic non-communicable diseases [9]. Two follow-ups have been conducted, and the third follow-up is currently underway. While this cohort study presents retention challenges that are common to conventional longitudinal cohort studies, other challenges have been identified. These challenges reflect the geographic and cultural environment of the Indigenous population being studied. This work will help to inform and assist researchers undertaking or planning similar studies in Indigenous and developing populations. We aim to report the follow-up rates of an Aboriginal Birth Cohort study and describe how they were achieved.

\section{Participants}

Babies were eligible for recruitment into the $A B C$ if they were singletons born January 1987- March 1990, to a mother recorded in the Delivery Suite Register of the Royal Darwin Hospital (RDH) as a self-identified Aboriginal. Of the 1253 babies eligible for recruitment, 686 were enrolled into the study (Wave-1). Recruitment was dependent on the availability of the recruiting paediatrician and although not randomly selected there was no significant differences in mean birth weight, sex ratio or the birth weight frequencies between those recruited and those not recruited [9]. Health care policy was for all women to deliver in hospital so women were relocated to the nearest hospital at 38 weeks or earlier if the delivery was deemed to be high risk. Hence the majority of the participants (70\%) came from rural, remote and very remote Aboriginal communities which maintain traditional connections to the land and their culture.

\section{Setting}

The RDH is the centre of health delivery for a large region of northern Australia. The Aboriginal communities are situated within this sparsely populated ( 0.2 people/ $\mathrm{km}^{2}$ ) area of approximately 900,000 $\mathrm{km}^{2}$ (347sq miles) with poor communication and transport infrastructures. This catchment area is similar to the combined area of California and New México, with a population density less than Alaska. Although urban rural disparities occur, the rural areas have a well established network of government health services.

\section{Methods}

Details of this prospective longitudinal study have been previously published $[9,10]$. In brief, follow-ups have been conducted at 11.4 years (Wave-2) and 18.2 years (Wave-3) with the current Wave-4 follow-up underway at approximately 26 years. Growth and nutritional measures, biomedical specimens and lifestyle questionnaires are directly collected from the participants at the point of contact.

\section{Ethics}

This study is conducted within the principles of the National Health Medical Research Council Road Map 11 which is a strategic framework for improving the health of Aboriginal and Torres Strait Islander people through research [11]. It adheres to the themes of respect, integrity, responsiveness, competency, and reciprocity, common to the ethical guidelines for research involving Indigenous peoples in Australia, Canada and New Zealand [12-14].

The study has approval from The Human Research Ethics Committee of the NT Department of Health and Families, and Menzies School of Health Research, including an Aboriginal Ethical Sub-committee which has the power of veto. Written consent was obtained in the form of an itemized consent, giving the participant capacity to refuse individual procedures (Additional file 1).

\section{Results}

\section{Follow up}

Twenty years after recruitment, vital status was determined for $87 \%$ of the cohort. Figure 1 shows that $86 \%$ and $72 \%$ of living participants were directly examined at mean ages 11.4 years (Wave -2) and 18.2 years (Wave-3).

Ninety three percent (93\%) and $83 \%$ of participants were traced at 11.4 and 18.2 years respectively. Traced participants not examined (78, Wave -2 and 102, Wave-3) were due to refusals, the costs of examining individuals in very remote locations and delays of planned trips due to cyclone warnings, unexpected community events or poor flying conditions. Of the initial cohort, 20 years after recruitment only 91 participants could not be located.

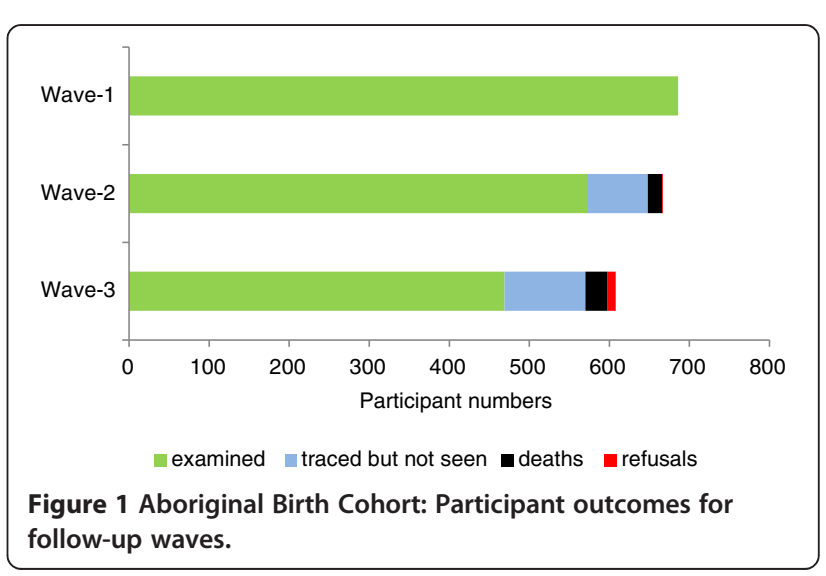




\section{Challenges and responding strategies}

The challenges of maintaining, tracing and undertaking data collection in this Indigenous cohort are predominantly of a logistical and cultural/linguistic nature.

For maintenance between follow-up waves, challenges related to the limited availability of good communication routes, with no television coverage and limited radio and newspapers in which to advertise and publicise the study. Personal participant contact is difficult between follow-ups as there are no individual household postal services, nor standard mobile phone coverage in remote areas. In larger communities there are fixed phone lines for the community council, school and health clinic, but in smaller communities phone contact is limited to a single solar powered phone, often not in working order.

There are cross-cultural differences between the researchers and the cohort participants as well as marked cultural diversity among the Aboriginal people within the cohort itself: Discreet communities may contain multiple land-owning clans, and this diversity is reflected in approximately 30 different dialects within the cohort region. As a result $70 \%$ of participants use English as a second language and in some cases, a third language.

Between waves, in order to develop confidence and familiarity with the project and the research team, we sought to establish the identity and legitimacy of the project and the research team members. In place of one to one contact, we fostered community relationships which helped identify key community members with local knowledge.

Key community people were important in all phases of the follow-up. They acted as project advocates, interpreters, helped with practical local navigation issues, facilitated community consultation and negotiation, and in some cases were employed as paid assistants (Table 1).

Photos of participants seen in the past were especially effective in fostering positive relationships and aiding in tracing. They provided concrete evidence that the

\section{Table 1 Aboriginal Birth Cohort: strategies used to address maintenance challenges}

\begin{tabular}{|c|c|}
\hline Aim & Responding strategies \\
\hline \multirow{7}{*}{$\begin{array}{l}\text { To establish project legitimacy } \\
\text { and identity }\end{array}$} & Study tag, "Clan Cohort", logo and ID cards developed \\
\hline & Regular updates in local newsletters for Aboriginal child and family wellbeing services \\
\hline & Articles published in Aboriginal and Torres Strait Islander Health Worker Journal \\
\hline & Discussions on Indigenous radio stations \\
\hline & Institutional Indigenous reference group presentations for consultation and negotiation \\
\hline & $\begin{array}{l}\text { Opportunistic informal discussion with Aboriginal Health Workers attending workshops and } \\
\text { conferences in city }\end{array}$ \\
\hline & $\begin{array}{l}\text { Bright cartoon posters with simple English posted around communities with story of the study, } \\
\text { its findings and overall long term objectives contributing to developing a sense of history }\end{array}$ \\
\hline \multirow[t]{3}{*}{ To establish researchers profiles } & $\begin{array}{l}\text { Continuity of the research team; cohort founder and recruiter still engaged with study, two other } \\
\text { senior researchers for } 12 \text { years }\end{array}$ \\
\hline & Researchers photos attached to leaflets and posters \\
\hline & Cartoon posters with recognizable caricatures of the researchers posted around communities \\
\hline \multirow[t]{5}{*}{$\begin{array}{l}\text { To develop community } \\
\text { relationships }\end{array}$} & $\begin{array}{l}\text { Developing community relationships with Elders, Aboriginal councils and community health clinics, } \\
\text { through phone, mail and personal meetings }\end{array}$ \\
\hline & Attending community events, art shows, open days and festivals \\
\hline & $\begin{array}{l}\text { Sending Christmas cards, thank you notes and study updates with pictures and diagrams to } \\
\text { community councils and clinics }\end{array}$ \\
\hline & Use of photo albums from current and previous follow-ups \\
\hline & $\begin{array}{l}\text { At end of community visit sending summary of de-identified community health findings to Elders, } \\
\text { council and health clinic }\end{array}$ \\
\hline \multirow{7}{*}{$\begin{array}{l}\text { To establish researcher } \\
\text { participant relationships }\end{array}$} & Cohort reference group presentations for advice on all aspects of study \\
\hline & Cohort participants invited to "Researcher Thank You Day "with media involved \\
\hline & Cartoon posters with simple English posted around communities \\
\hline & Study aids with large non-verbal visual component accompanied by written information sheets \\
\hline & Biomedical results in visual form given to cohort participants \\
\hline & Cross-cultural training provided to researchers \\
\hline & Limited field staff turnover \\
\hline
\end{tabular}


researchers were known to the community, and participants reported enjoying seeing themselves, family members and peers in a hard copy album.

The procedures for locating participants have previously been described [10]. Briefly a multiphase method was used with separate arms for rural and urban participants. The locating phase was affected by the poor communication and linguistic challenges of the maintenance phase. While only a few urban participants had individual post boxes and even fewer responded to an introductory letter, the letter did serve as an ice breaker when face to face contact was made later. For rural visits, a generic community visit flow chart served as check list for staff organizing a visit see Figure 2 .

Name changes and mobility also complicated localizing participants. When checked at the age of four years, $30 \%$ of participants had changed their name from the recruitment name. Participant mobility occurs within areas defined by kinship ties and within four years $18 \%$ had changed their place of residence since recruitment [9]. Importantly, family links between specific communities were identified (Table 2).

Data relating to growth and nutritional measures, biomedical specimens and lifestyle questionnaires were

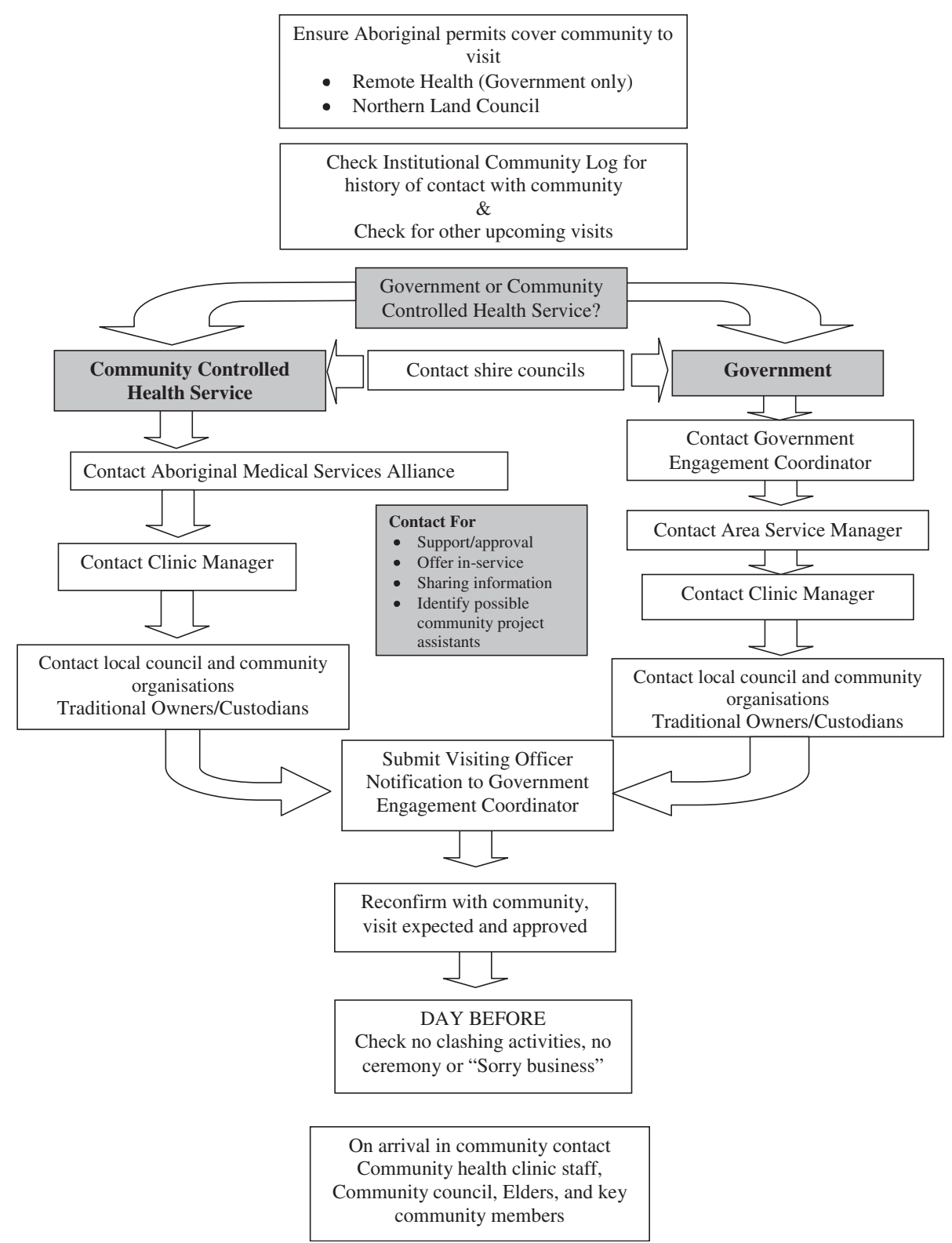

Figure 2 Aboriginal birth cohort: Community visit flow chart. 
Table 2 Aboriginal Birth Cohort: strategies used to address locating challenges

\begin{tabular}{ll}
\hline Aim & Responding strategies \\
\hline Rural & Key significant people identified in each large community and employed \\
& List of cohort members thought to be in community sent to them requesting confirmation \\
& of participant presence \\
& Door to door visits yielded best results \\
Urban & Letter useful \\
& Multiple personal identifiers including unique hospital number, name, sex, date of birth and \\
Co positively identify & Community residence at time of birth \\
participants & Recowing photograph to community members \\
& Key Aboriginal community assistants employed with local knowledge of community movements \\
& Visits to remote communities with strong kinship ties scheduled close together \\
& All participants sign individual consents for image photograph to be taken and for photograph to \\
be used for promotion, publicity and tracing
\end{tabular}

directly collected from the participants. Logistic challenges related to transporting the researchers and their equipment to key remote community hubs. There were also challenges related to the methods of giving information to, and seeking consent from participants. Consent and information sheets evolved with the increasing age of the cohort and changing ethical considerations leading finally to substantial use of visual aids and a written information sheet in simple English accompanying a visually enhanced staged consent form (Additional file 1). In Wave-3, $10 \%$ of participants chose to selectively opt out of different assessments within the staged consent (Table 3).

\section{Discussion}

The Aboriginal Birth Cohort Study demonstrates that satisfactory follow-up rates of an Indigenous cohort with traditional characteristics are possible and scientific rigor can be maintained in a challenging setting. The overall vital status determined for $83 \%$ of participants and the physical examination of $72 \%$ of living participants at 20 years after recruitment are indicative of the successful retention strategies that have evolved over the course of this Indigenous population study.

These follow-up rates are comparable to other cohort studies in developed countries [15-17], which have retention techniques that were unavailable in our study. Such techniques include mail surveys, telephone surveys, birthday cards, sending mobile phone reminders and newsletters [18]. Follow-up rates of cohorts in developing populations with conditions in contrast to the $\mathrm{ABC}$ study are similar or higher than our study. At 3 years, a follow up rate of $83 \%$ was achieved in Vellore slum birth cohort [19] (catchment area $2.2 \mathrm{~km}^{2}$, population density of 17,000 per $\mathrm{km}^{2}$ ), while a Mysore birth cohort achieved $94 \%$ follow up rate at 9-10 years [20]. The Pelatos (Brazil) Birth Cohort study has a $77 \%$ follow-up rate at 23 years, achieved by visiting 98,000 households in the city and using educational data bases and telephone directories [21].

Our cohort study is consistent with other reports of hard-to-reach and marginalised populations, showing retention is often manual and labour intensive and requires flexibility, persistence and ingenuity [22]. The flexibility for this study extended to planning around weather conditions, addressing community geographic and cultural considerations and individual participant's needs. Notable in this study is the reliance on community support and goodwill facilitated by extensive consultation and negotiation and the researchers' flexibility, respect and transparent communication.

Developing a profile of the $\mathrm{ABC}$ study and the research team has been critical in establishing the legitimacy of the study and has gathered momentum with time. Continuity of field workers and particularly a male Aboriginal research team member employed over two adult data collection waves has been pivotal in engaging with shy Aboriginal men and cementing the legitimacy of the study. The inclusion of local Aboriginal research assistants remains absolutely essential to address very specific community cultural and logistic issues, arising from the large diversity in Aboriginal communities.

Consultation was sought from an institutional Aboriginal reference group which also contributed methods to engage Aboriginal communities. An ABC reference group drawn from the participants has met regularly to discuss research approaches. This small group has been invited to 'Researcher Thank You Days' with the local 
Table 3 Aboriginal Birth Cohort : data collection, challenges and strategies

\begin{tabular}{|c|c|}
\hline Aim & Challenges \\
\hline \multirow[t]{4}{*}{ To gain access to participants } & Rural \\
\hline & $\begin{array}{l}\text { Vast, sparsely populated area rem } \\
\text { communities }\end{array}$ \\
\hline & Poor unsealed roads and runway \\
\hline & $\begin{array}{l}\text { 3-4 months monsoon flooding o } \\
\text { roads and airstrips }\end{array}$ \\
\hline
\end{tabular}

To consult and negotiate with communities to gain approval and fit with community activities

To organise researcher team and satisfy needs

To transport equipment

To have constant power supply

To explain procedures

To collect data

To do a venepuncture

To transport biological specimen to distance laboratory

To gain informed consent

To avoid clashing with community activities to

Urban

Failure to respond to letter

Multiple and support required

Limited space

Space and weight restrictions

Travel unsealed rough roads procedures procedures

Growth and nutritional data considered first priority

Lack of private space

Participants scared of procedure procedures

Ceremonies and "sorry business" Other agency and government

\section{Responding strategies}

Priority of dry season community assessments

Self-sufficient four wheel drive travel, fuel, food, water and satellite phone

Researchers trained in four wheel driving

Local research assistants help navigate unmarked roads to community

Road travel supplemented by light aircraft charter or commercial travel to larger hubs

A research assistant with pilots licence an advantage

Door to door transport provided

Difficulties getting to appointments

Limited food outlets

Power unreliable in communities

English second language, participants unfamiliar with scientific terms and

Participants shy and unfamiliar with

Preserving blood and urine samples

English second language, participants unfamiliar with scientific terms and department visits
Central clinic used for assessment

Generic flow chart developed to be used for each community (Figure 2)

Small multi-skilled research team

Personal breakfast and lunch food, team roster for night meals Light equipment e.g., hand held ultrasound and vitalograph Researchers' personal possessions limited Robust equipment purchased and wrapped in bubble wrap All equipment capable of running with battery power Visual aids, pictures drawings and demonstrations Simple English assisted by employment of local Aboriginal assistant

Explanations in groups, max 4 gender matched with researcher

Siblings, cousins and friends data collection scheduled together for procedures

Triage of data collection making sure primary growth and nutritional data always obtained

Researchers carry multiple sarong lengths to screen off private spaces

Local anaesthetic cream used

Observation of others consenting to be watched during procedure

Blood centrifuged at point of collection

Serum separated and placed in specific testing tubes

Specimens maintained at low temperature in cold storage boxes or fridges

Transported to central laboratory on government planes from hub if delays expected

Staged consent form (Additional file 1) accompanied by visual

Day before a planned community visit check still appropriate to visit

Flexibility of researchers to change plans at short notice to accommodate unexpected traditional ceremonies and other important community visitors aids explained by gender matched research assistant 


\section{Table 3 Aboriginal Birth Cohort : data collection, challenges and strategies (Continued)}

\begin{tabular}{|c|c|c|}
\hline $\begin{array}{l}\text { To use local Aboriginal interpreters and } \\
\text { research assistant }\end{array}$ & Kinship and avoidance issues & $\begin{array}{l}\text { Researchers understand and accommodate kinship and } \\
\text { avoidance issues when working with Aboriginal people in a } \\
\text { community }\end{array}$ \\
\hline \multirow[t]{2}{*}{ Reimbursement for time spent } & \multirow{2}{*}{$\begin{array}{l}\text { Concerns of coercion or inappropriate } \\
\text { use of given money }\end{array}$} & Food and drink after fasting \\
\hline & & $\begin{array}{l}\text { Wave- } 3 \text { Canvas bag with wrist band and water bottle with } \\
\text { study logo, tooth brush, tooth paste and health promotion } \\
\text { flyers }\end{array}$ \\
\hline
\end{tabular}

media present, and have taken part in media activities such as a television segment focussing on the $A B C$ study.

The ABC study has been conducted within the principles of the Road Map 11 strategy, [11] including employment of local Aboriginal research assistants and training for the male research assistant. The Australian ethical guideline themes for conducting research with Indigenous people and communities have provided an ethical framework for the study with strategies evolving over time. Initial consent was given by the mothers on behalf of the participants at birth. Later at 11 years of age formal consent was again given by the mother but the child's wishes in regard to specific procedures were respected. For adult participants, a staged consent form for data collection has been developed instead of blanket consent for all procedures (Additional file 1). This gives participants control over data collection where $10 \%$ of participants felt able to opt out of specific procedures at 18 years of age.

In view of the longitudinal nature of the study and the need for co-operation over a lifetime, individual research experiences are limited to 2 hours or less with food and drinks available after fasting bloods are taken.

This is the first documentation of practical strategies used to conduct a longitudinal study of an Indigenous birth cohort. It relates to an under-served ethnic minority group with traditional connections to land and culture and addresses the ethical guidelines for conducting research with Indigenous people. There are other reports relating to marginalised ethnic minorities [23] and minority research participants [24] but the populations described are not traditional and the retention strategies of mass mailing, emails and telephone prompts are still used in these cohorts.

The developed strategies are based on researchers experiences and have been refined over the course of the study, where two authors have been involved for 26 years and 15 years respectively. The follow-up loss of only $13 \%$ after 20 years suggests the current package of strategies is successful; however currently we are unable to disentangle the cost effectiveness of specific strategies in the package.

The strategies developed relate to diverse Indigenous populations in the northern part of Australia.
Generalisation to other indigenous populations and or other Australian indigenous groups may be limited and the strategies reported may not have direct application in other settings. However some of our innovations may serve as templates for modification and encourage researchers to develop other non-conventional approaches suited to individual research settings.

The first two decades of this cohort have built significant foundations for its future. Using the approaches refined over time we are currently well placed to continue this life course study of an Indigenous birth cohort provided we maintain the same extensive consultation and negotiation processes with flexibility, respect and transparent communication.

\section{Conclusions}

Satisfactory follow-up rates of a prospective longitudinal Indigenous birth cohort with traditional characteristics are possible while maintaining scientific rigor in a challenging setting. Approaches needed, include flexibility, respect, and transparent communication along with the adoption of culturally sensitive behaviours.

\section{Additional file}

Additional file 1: Aboriginal Birth Cohort: Itemised consent form.

\section{Competing interests}

The authors declare that they have no competing interests.

\section{Authors' contributions}

$M L$ drove the manuscript concept, drafted the initial drafts and organised the references. SS modified draft, tables and figures and added content. GS reviewed drafts, modified tables and added content. All authors read and approved the final manuscript.

\section{Acknowledgements}

We thank the young adults belonging to the cohort for their continued co-operation, their mothers for agreeing to first enrol them and all the individuals who helped in the urban and rural locations.

\section{Funding}

This work was supported by the National Health and Medical Research Council of Australia (436011, 137203, 320860; the Channel 7 Children's Research Foundation of South Australia (2006); the National Heart Foundation (G04D1504) the Colonial Foundation, Diabetes Australia, Pfizer and a Northern Territory Government Research and Innovation Grant (2006) 


\section{Author details}

'C/-Menzies School of Health Research, Institute of Advanced Studies, Charles Darwin University, PO Box 41096, Casuarina, NT 0810, Australia. ${ }^{2}$ Charles Darwin University \& Flinders | School of Medicine Flinders University, PO Box 41096, Casuarina, NT 0811, Australia.

Received: 21 October 2013 Accepted: 18 February 2014 Published: 26 February 2014

\section{References}

1. Wadsworth M, Kuh D, Richards M, Hardy R: Cohort profile: the 1946 national birth cohort (MRC national survey of health and development). Int J Epidemiol 2006, 35(1):49-54.

2. Pearce MS, Unwin NC, Parker L, Craft AW: Cohort profile: the Newcastle thousand families 1947 birth cohort. Int J Epidemiol 2009, 38:932-937.

3. Blair EM, Zubrick SR, Cox AH: The western Australian aboriginal child health survey: findings to date on adolescents. Med J Aust 2005, 183(8):433-435.

4. Richter L, Norris S, Pettifor J, Yach D, Cameron N: Cohort profile: Mandela's children: the 1990 birth to twenty study in South Africa. Int J Epidemiol 2007, 36(3):504-511.

5. Santos IS, Barros AJ, Matijasevich A, Domingues MR, Barros FC, Victora CG: Cohort profile: the 2004 Pelotas (Brazil) birth cohort study. Int J Epidemiol 2011, 40(6):1461-1468.

6. Victora CG, Hallal PC, Araújo CL, Menezes AM, Wells JC, Barros FC: Cohort profile: the 1993 Pelotas (Brazil) birth cohort study. Int J Epidemiol 2008, 37(4):704-709.

7. Richter LM, Victora CG, Hallal PC, Adair LS, Bhargava SK, Fall CH, Lee N, Martorell R, Norris SA, Sachdev HS, Stein AD, COHORTS Group: Cohort profile: the consortium of health-orientated research in transitioning societies. Int J Epidemio/ 2012, 41(3):621-626.

8. Boutayeb A, Boutayeb $\mathrm{S}$ : The burden of non communicable diseases in developing countries. In J Equity in Health 2005, 4(1):2.

9. Sayers SM, Mackerras D, Singh G, Bucens I, Flynn K, Reid A: An Australian Aboriginal birth cohort: a unique resource for a life course study of an Indigenous population. A study protocol. BMC Int Health Hum Rights 2003, 3(1):1.

10. Sayers S, Singh G, Mackerras D, Lawrance M, Gunthorpe W, Jamieson L, Davison B, Schutz K, Fitz J: Australian Aboriginal Birth Cohort study: follow-up processes at 20 years. BMC Int Health Hum Rights 2009, 9:23.

11. National Health and Medical Research Council (NHMRC): The NHMRC road Map 11: a strategic framework for improving the health of Aboriginal and Torres Strait Islander people through research. Commonwealth of Australia; 2010.

12. Australian Institute of Aboriginal and Torres Strait Islander Studies (AIATSIS): Guidelines for Ethical Research in Australian Indigenous Studies. Canberra; 2011. http://www.aiatsis.gov.au/_files/research/ethics.pdf.

13. Tri-Council Policy Statement: Ethical Conduct for Research Involving Humans, December 2010. http://pre.ethics.gc.ca/eng/policy-politique/initiatives/tcps2eptc2/Default/.

14. Social Policy Evaluation and Research Committee: SPEaR Good Practice Guidelines 2008; 2008. http://www.spear.govt.nz/good-practice/index.html.

15. Dalziel SR, Parag V, Rodgers A, Harding JE: Cardiovascular risk factors at age 30 following preterm birth. Int J Epidemiol 2007, 36(4):907-915.

16. Ivan Eijsden M, Vrijkotte TGM, Gmeke RJBJ, van der Walm MF: Cohort Profile: The Amsterdam Born Children and their Development (ABCD) Study. Int J Epidemiol 2011, 40:1176-1186

17. Boyd A, Golding J, Macleod J, Lawlor D, Fraser A, Henderson J, Molloy L: Cohort Profile: The 'Children of the $90 s^{\prime}$ - the index offspring of the Avon Longitudinal Study of Parents and Children. Int J Epidemiol 2013, 42(1):111-127

18. Lucas PJ, Allnock D, Jessiman T: How are European birth-cohort studies engaging and consulting with young cohort members? BMC Med Res Methodol 2013, 13:56.

19. Rehman AM, Gladstone BP, Verghese VP, Muliyil J, Jaffar S, Kang G: Chronic growth faltering amongst a birth cohort of Indian children begins prior to weaning and is highly prevalent at three years of age. Nutr J 2009, 8:44.

20. Veena SR, Krishnaveni GV, Srinivasan K, Wills AK, Muthayya S, Kurpad AV, Yajnik CS, Fall CH: Higher maternal plasma folate but not vitamin B-12 concentrations during pregnancy are associated with better cognitive function scores in 9- to 10- year-old children in south India. J Nutr 2010, 140:1014-1022.

21. Victora CG, Barros FC: Cohort profile: the 1982 Pelotas (Brazil) birth cohort study. Int J Epidemiol 2006, 35(2):237-242.

22. Bindman AB, Grumbach K, Keane D, Lurie N: Collecting data to evaluate the effect of health policies on vulnerable populations. Fam Med 1993, 25(2):114-119.

23. Kuhns LM, Vasquez R, Ramirez-Valles J: Researching special populations: retention of Latino gay and bisexual men and transgender persons in longitudinal health research. Health Educ Res 2008, 23(5):814-825.

24. Yancey AK, Ortega AN, Kumanyika SK: Effective recruitment and retention of minority research particpants. Ann Rev Public health 2006, 27:1-28.

doi:10.1186/1471-2288-14-31

Cite this article as: Lawrance et al:: Challenges and strategies for cohort retention and data collection in an indigenous population: Australian Aboriginal Birth Cohort. BMC Medical Research Methodology 2014 14:31.

\section{Submit your next manuscript to BioMed Central and take full advantage of:}

- Convenient online submission

- Thorough peer review

- No space constraints or color figure charges

- Immediate publication on acceptance

- Inclusion in PubMed, CAS, Scopus and Google Scholar

- Research which is freely available for redistribution 